\title{
Baseball pitching and softball pitching: Why the perplexity?
}

\author{
Gretchen D Oliver* \\ Professor, School of Kinesiology, Sports Medicine \& Movement Lab, Auburn University, USA
}

\begin{abstract}
Traditionally, the baseball pitch is considered overhanded or overhead while the softball pitch is underhanded. Within this traditional rhetoric, one assumes vast differences in the two pitching styles and thus, the common misconception of the underhand softball pitch producing less stress to the upper extremity when compared to the overhand baseball pitch. Though if we take a step away from the traditional rhetoric, we can describe both the baseball and softball pitch as dynamic upper extremity movements that requires the body to efficiently generate and transfer energy in a proximal to distal sequencing. The reality is that the true difference between the two pitches is the arm slot.
\end{abstract}

\section{Background and purpose}

Though times are changing, it still seems that we are behind on understanding the mechanics of the windmill softball pitch from a clinical sports medicine perspective of injury prevention and performance enhancement. Within the sports medicine community, there is considerable interest in youth baseball pitching and injury prevention. Since 1996 Dr. James Andrews and the American Sports Medicine Institute have worked to not only regulate pitch counts in Little League Baseball [1], but also to educate the masses regarding baseball pitching, injury susceptibility, and injury prevention [2-8]. Throughout the years of youth baseball research, a common consensus of risk factors has emerged. One particular modifiable risk factor that is thoroughly recognized within throwing and injury prevention is depicting the body as a kinetic chain and thus kinetic chain efficiency as a means of improving dynamic throwing mechanics [9]. Therefore, in the past 20 years, sports medicine research has been successful in emphasizing kinetic chain efficiency for proper pitching mechanics, as well as implementing organizational sanctions to monitor and limit pitch counts in an attempt to curtail fatigue in youth baseball pitchers.

Often referred to as a scaled-down version of baseball, is the sport of fast-pitch softball. Though the differences between baseball and softball are represented in all positions, the major difference is the pitching style. Due to the repetitive high demand of throwing that occurs within the two sports, injuries are an inherent risk. Copious efforts have researched the pathophysiology and predisposing risk factors for these overuse injuries in baseball, however there are scarce research determining underlying the pathophysiology and risk factors involved in injuries sustained in softball pitchers. Therefore, the purpose this commentary is to discuss how similar baseball and softball pitching can be from an injury prevention approach when examining the two movements as an upper extremity dynamic movement.

\section{The kinetic chain and dynamic upper extremity movement}

A biomechanical model for striking and throwing is an open-linked system of segments working in a proximal to distal sequence with the goal to impart high velocity or force on the most distal segment [10]. Therefore, the ultimate velocity of the distal segment is dependent upon the segmental histories of the most proximal segments. Dynamic upper extremity movements such as throwing, and pitching occur as a result of the body working efficiently as a kinetic chain. Efficient utilization of the body as a kinetic chain allows for coordinated segmental sequencing of activation, movement and stability [10,11]. Throwing and pitching are dynamic upper extremity movements that requires the total kinetic chain to sequentially coordinate force development and transfer from the most proximal segments of the lower extremity to the most distal segments of the wrist and hand. Specifically, the kinetic chain must provide proximal stability for distal mobility; maximal force development proximally in the lower extremity and lumbopelvic-hip complex (LPHC) and transfer it through the upper extremity to produce optimal distal mobility. When we consider anticipatory movements, it is the trunk and lower extremity that are initiated prior to the upper extremity dynamic movement $[12,13]$. Thus, proper utilization of the kinetic chain during dynamic upper extremity movements allows maximal force to be developed in the LPHC which then can efficiently be transferred to the wrist and hand $[9,14]$.

\section{Kinetic chain deficits in dynamic upper movement}

Pathologic deficits with the dynamic throwing shoulder are about the lower extremity, LPHC, scapula, and shoulder [15]. In both pitching styles, baseball and softball, the athlete has to maintain trunk control via LPHC stability over the stance leg (throwing side leg) in attempt to control their center of mass as they stride to position their stride foot in line with the target $[9,16-18]$. The importance of controlling

${ }^{\star}$ Correspondence to: Gretchen D Oliver PhD, FACSM, ATC, CES, Professor, School of Kinesiology, Sports Medicine \& Movement Lab, Auburn University, USA, E-mail: gdo0001@auburn.edu

Key words: arm slot, injury prevention, throwing, rehabilitation, windmill softball pitch

Received: April 30, 2020; Accepted: May 12, 2020; Published: May 15, 2020 
one's center of mass over base of support is an attempt to engage the stride leg in pulling the body forward during the acceleration phase [19]. Additionally, scapular control and mobility is essential to position the humerus for acceleration [20,21]. Both pitch styles utilize the aforementioned concepts with the ultimate goal of producing ball spin and velocity to the desired target.

\section{What is the difference between the two pitch styles?}

Traditionally, the baseball pitch is considered overhanded or overhead while the softball pitch is underhanded. Within this traditional description one assumes vast differences in the two pitching styles and thus, the common misconception of the underhanded softball pitch producing less stress to the upper extremity when compared to the overhand baseball pitch [22]. Tough it is has been continually reported that the stresses to the upper extremity in softball pitching are similar to that in baseball pitching $[17,22-25]$ the traditional opinion of overhand versus underhand neglects the reality. The reality is that there is a difference in arm slot between the two pitching styles. Within baseball pitching there are three common arm slots: overhand (arm near vertical at approximately $\left(140^{\circ}\right.$ from the ground)), sidearm (arm near horizontal $\left(70^{\circ}\right.$ to $90^{\circ}$ from the ground)) and 3-quarter (approximately halfway between overhand and sidearm $\left(50^{\circ}\right.$ to $60^{\circ}$ from the ground)); and one additional slot, that is not as common, is submarine (arm is below sidearm similar to 3 -quarter (approaching $50^{\circ}$ or less from the ground)) [26,27].

Turning away from the traditional rhetoric of the overhand baseball pitch and the underhand softball pitch, let's consider the two pitching styles as dynamic upper extremity movements that utilize different arm slots. As depicted in Figure 1, the differences in style now becomes a bit blurred. Though there are more options for different arm slots in baseball pitching, the softball pitching arm slot of underhand (arm near vertical $\left(0^{\circ}\right.$ to $18^{\circ}$ from the ground) is more specific [17]. Within the baseball literature regarding injury prevention and performance enhancement, the common notion is that the baseball pitch is a dynamic upper extremity movement utilizing an efficient kinetic chain of proximal stability for distal mobility $[9,10]$. Thus, the fundamental inquiry; why do we set aside the mechanics of softball pitching as our caveat for injury prevention and performance enhancement for the softball pitcher?

Current softball biomechanaical data are revealing increasing similarities to the baseball pitch. In an examination of upper extremity pain and pitching mechanics in collegiate softball pitchers, it was found that those with upper extremity pain displayed greater shoulder abduction (arm further away from the body or the vertical) in the acceleration phase; this is similar to what has been found in baseball
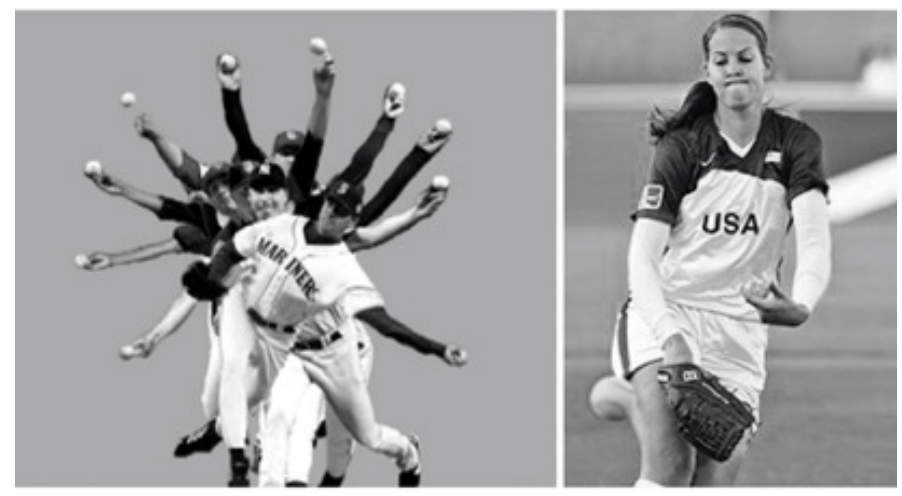

Figure 1. Arm slots for baseball and softball pitching pitchers. Specifically, a more extended elbow at the beginning of the acceleration phase, during the baseball pitch, is associated with greater ulnar collateral stress $[28,29]$. Additionally, female softball pitchers with upper extremity pain displayed less trunk lateral flexion to the throwing side than those without pain [17]. Again, these softball findings are similar to what has been reported in the baseball literature regarding the importance of trunk positioning; greater rotation and lateral flexion to the throwing side for the most efficient energy transfer [30,31]. Thus, it was suggested that the pain-free group of softball pitchers transferred energy more efficiently from their lower extremity and LPHC to their upper extremity, due to the greater degree of trunk lateral flexion [17]. These latest data reiterate the further classification of baseball and softball pitching as dynamic upper extremity movements, the similar findings in both upper extremity and trunk kinematics are not surprising. As it is well documented that trunk or LPHC instability affects throwing mechanics, and ideally efficient mechanics requires an athlete to generate the most energy within the lower extremity and LPHC, [32-35] and transfer up through the trunk and on to the hand for ball release [14].

To further expound on the body working as a kinetic chain during dynamic upper extremity movement, we would be remiss not to mention the two studies performed by Barfield et al. [36,37] regarding the utilization of the glove arm in baseball and softball pitching. Previously, it has been documented that the utilization of the glove arm in baseball pitching is associated with trunk positioning during the baseball pitch [38]. Thus, follow up investigation by Barfield et al. reiterated the importance of a more active glove arm in youth baseball pitchers could assist in not only optimal trunk positioning for the most efficient use of energy transfer from the lower extremity but also, decreased throwing arm kinetics [37]. Then to follow-up, and theoretically support the notion of viewing both baseball and softball as dynamic upper extremity movements with different arm slots, Barfield and colleagues examined the influence of an active glove arm in softball pitching and the association with segmental sequencing of the pelvis and trunk as well as pitching arm kinetics [36]. Similar to the association of an active glove arm in baseball pitching, an active glove arm in softball pitching was also predictive of a more efficient kinetic chain during the softball pitching motion $[36,37]$.

\section{Discussion}

Though the traditional rhetoric of the comparison of baseball and softball pitching is to classify baseball as overhand and softball as underhand, conventional wisdom encourages us to elucidate that both baseball and softball pitching are dynamic upper extremity movements. Both pitching styles are considered throwing and thus throwing is an open-linked system of segments working in a proximal to distal sequence with the goal to impart high velocity or force on the most distal segment [10].

\section{Conclusion}

Thus, the two pitching styles employ the same theoretical framework of proximal stability for distal mobility with the main difference being the arm slot. As sports medicine professionals, we should embrace the overall fact that throwing is throwing is throwing, then hopefully we can step out of hiding behind the unknows of softball pitching and work for a stronger healthier athlete.

\section{Conflicts of interest}

The author has no financial affiliation (including research funding) or involvement with any commercial organization that has a direct financial interest in any matter included in this manuscript. 


\section{References}

1. Andrews J, Fleisig G (1996) How many pitches should I allow my child to throw? 1-6.

2. Andrews JR, Fleisig GS (1998) Preventing throwing injuries. J Orthop Sports Phys Ther 27: 187-188. [Crossref]

3. Parks ED, Ray TR (2009) Prevention of overuse injuries in young baseball pitchers. Sports Health 1: 514-517.

4. Olsen SJ, Fleisig GS, Dun S, Loftice J, Andrews JR, et al. (2006) Risk factors for shoulder and elbow injuries in adolescent baseball pitchers. Am J Sports Med 34: 905912

5. Fleisig GS, Andrews JR, Cutter GR, Weber A, Loftice J, et al. (2011) Risk of serious injury for young baseball pitchers: a 10-year prospective study. Am J Sports Med 39: $253-257$

6. Andrews JR, Wilk K (1994) Shoulder injuries in baseball. In: Andrews JR, Wilk K, editors. The Athlete's Shoulder. New York: CHurchill Livingstone 369-389.

7. Wilk K, Obma P, Simpson CD, Cain EL, Dugas JR, et al. (2009) Shoulder injuries in the overhead athelte. Journal of Orthopaedic and Sports Physical Therapy 39: 38-54. [Crossref]

8. Fleisig G, Chu Y, Weber A, Andrews J (2009) Variability in baseball pitching biomechanics among various levels of competition. Sports Biomech 8: 10-21.

9. Chu SK, Jayabalan P, Kibler WB, Press J (2016) The kinetic chain revisited: New concepts on throwing mechanics and injury. PMR 8: S69-S77.

10. Putnam CA (1993) Sequential motions of body segments in striking and throwing skills: descriptions and explanations. J Biomech 26: 125-135.

11. Kibler WB (1995) Biomechanical analysis of the shoulder during tennis activities. Clin Sports Med 14: 79-85. [Crossref]

12. Zattara M, Bouisset S (1998) Posturo-kinetic organization during hte early phase of voluntary upper limb movement, 1: Normal subjects. Journal of Neurology, Neurosurgery and Psychiatry 51: 956-965.

13. Bouisset S, Zattara M (1981) A sequence of postural movements precedes voluntary movement. Neuroscience Letters 22: 263-270.

14. Kibler WB, Press J, Sciascia A (2006) The role of core stability in athletic function. Sports Med 36: 189-198.

15. Kibler WB, Wilkes T, Sciascia A (2013) Mechanics and pathomechanics in the overhead athlete. Clin Sports Med 32: 637-651. [Crossref]

16. Oliver GD, Plummer HA, Washington J, Weimar WH, Brambeck A, et al. (2019) Effects of game performance on softball pitchers and catchers. $J$ Strength Cond Res 33: 466-473.

17. Oliver GD, Gilmer G, Anz AW, Friesen K, Brittain A, et al. (2018) Upper extremity pain and pitching mechanics in NCAA Division I softball. International Journal of Sports Medicine 39: 929-935. [Crossref]

18. Oliver GD, Dwelly PM, Kwon YH (2010) Kinematic motion of the windmill softball pitch in prepubescent and pubescent girls. J Strength Cond Res 24: 2400-2407. [Crossref]

19. Oliver GD, Friesen K, Barfield J, Giordano K, Anz AW, et al. (2019) Association of upper extremity pain with softball pitching kinematics and kinetics. Ortho $J$ Sports Med 7: 2325967119865171
20. Burkhart SS, Morgan CD, Kibler WB (2003) The disabled throwing shoudler: Spectrum of pathology. Part III: the SICK scapula, scapular dyskinesis, the kinetic chain, and rehabilitation. Arthroscopy 19: 641-661.

21. Kibler WB (1998) The role of the scapula in athletic shoulder function. Am J Sports Med 26: 325-337.

22. Barrentine SW, Fleisig GS, Whiteside JA, Escamilla RF, Andrews JR, et al. (1998) Biomechanics of windmill softball pitching with implications about injury mechanisms at the shoulder and elbow. J Orthop Sports Phys Ther 28: 405-415.

23. Werner SL, Jones DG, Guido JA, Brunet ME (2006) Kinematics and kinetics of elite windmill softball pitching. Am J Sports Med 34: 597-603. [Crossref]

24. Guido JA, Werner SL, Meister K (2009) Lower-extremity ground reaction forces in collegiate baseball pitchers. J Strength Cond Res 26: 1782-1785.

25. Rojas IL, Provencher MT, Bhatia S, Foucher KC, Bach BR, et al. (2009) Biceps activity during windmill softball pitching: injury implications and comparison with overhand throwing. Am J Sports Med 37: 558-565.

26. Brooks DI, Fleisig G, Pavlidis H (2015) Delivery angle determines pitch movement: Evidence from biomechanics and pitch tracking. In: Miller S, Wojciechowski J, editors. Baseball Prospectus. Nashville, TN: Wiley General Trade. 443-446.

27. Escamilla RF, Slowik JS, Diffendaffer AZ, Fleisig G (2018) Differences among overhand, 3-quarter, and sidearm pitching biomechanics in professional baseball players. Journal of Applied Biomechanics 34: 377-385. [Crossref]

28. Fortenbaugh D, Fleisig GS, Andrews JR (2009) Baseball pitching biomechanics in relation to injury risk and performance. Sports Health 1: 314-320.

29. Werner SL, Murray b TA, Hawkins RJ, Gill TJ (2002) Relationship between throwing mechanics and elbow valgus in professional baseball pitchers. Journal of Shoulder and Elbow Surgery 11: 151-155.

30. Kageyama M, Sugiyama T, Kanehisa H, Maeda A (2015) Difference between adolescen and collegiate baseball pitchers in kinematics and kinetics of the lower limbs and trunk during pitching motion. Journal of Sports Science \& Medicine 14: 246-255. [Crossref]

31. Tanaka H, Hayashi T, Inui H, Ninomiya H, Muto T, et al. (2016) Influence of combinations of shoulder, elbow and trunk orientation on elbow joint loads in youth baseball pitchers. Orthopaedic Journal of Sports Medicine 4: 2325967116S0020.

32. Laudner KG, Wong R, Meister K (2018) The influence of lumbopelvic control on shoulder and elbow kinetics in elite baseball pitchers. J Shoulder Elbow Surg. [Crossref]

33. Gilmer GG, Washington JK, Dugas J, Andrews J, Oliver GD (2017) The role of lumbopelvic-hip complex stability in softball throwing mechanics. J Sport Rehabil.

34. Oliver GD (2014) Relationship between gluteal muscle activation and upper extremity kinematics and kinetics in softball position players. Med Biol Eng Comput 52: 265-270.

35. Plummer H, Oliver GD (2014) The relationship between gluteal muscle activation and throwing kinematics in baseball and softball catchers. Journal of Strength and Conditioning Research 28: 87-96.

36. Barfield J, Anz AW, Osterman C, Andrews J, Oliver GD. et al. (2019) The influence of an active glove arm in softball pitching: A biomechanical analysis. Int J Sports Med. [Crossref]

37. Barfield J, Anz AW, Andrews J, Oliver GD (2018) Relationship of glove arm kinematic with established pitching kinematic and kinetic variables among youth baseball pitchers. Orthop J Sports Med 6: 1-6. [Crossref]

38. Ishida K, Hirano Y (2004) Effects of non-throwing arm on trunk and throwing arm movements in baseball pitching. International Journal of Sport and Health Science 2: $119-128$.

Copyright: (C2020 Oliver GD. This is an open-access article distributed under the terms of the Creative Commons Attribution License, which permits unrestricted use, distribution, and reproduction in any medium, provided the original author and source are credited. 